SANO95-1753C

\title{
SYNTHESIS OF SURFACTANT-TEMPLATED MESOPOROUS MATERIALS FROM HOMOGENEOUS SOLUTIONS
}

\section{RECEIVED \\ AUG 171995 \\ OSTI}

\author{
Mark T. Anderson, James E. Martin, Judy Odinek, Paula Newcomer \\ Sandia National Laboratories \\ P.O. Box 5800 \\ Albuquerque, NM 87185
}

\section{CLASSIFICATION OF POROUS MATERIALS}

Porous materials are grouped by IUPAC into three classes ${ }^{1}$ based on their pore diameters, $d$ : (1) microporous - defined as $d<20 \AA$; (2) mesoporous - defined as $20 \leq d \leq$ $500 \AA$; and (3) macroporous - defined as $d>500 \AA$. The classification scheme does not explicitly take into account pore size distribution (PSD). Narrow PSDs can give rise to interesting and important size and shape dependent separation, adsorption; and catalytic properties. Mesoporous materials have pore apertures similar in size to small biological molecules, macromolecules, metal clusters, and organometallic compounds. Mesoporous materials that have narrow PSDs may thus be useful as hosts, supports, catalysts, or separation media for these species. Their PSDs depend critically on the method used to synthesize them.

\section{SYNTHESIS OF MESOPHASES: TEMPLATES LEAD TO PERIODICITY}

In general, three approaches are used to synthesize inorganic mesoporous materials, (1) propping layered materials with pillars, ${ }^{2}$ (2) aggregating small precursors to form porous gels, ${ }^{3}$ or (3) templating inorganic species around organic groups. ${ }^{2}$

In the first approach, organic or inorganic pillars are intercalated into inorganic layered hosts. The pillars prop the layers apart and create pores. The diffusion of the pillars into the host leads to a broad distribution of pillar-pillar distances. This anisotropy leads to nonperiodic structures with broad pore size distributions.

In the second approach, small silica species, inorganic polymers are allowed to aggregate and eventually to gel. The process generally leads to amorphous materials that have broad pore size distributions. The diffusion paths through the pore system are quite tortuous. 


\section{DISCLAIMER}

Portions of this document may be illegible in electronic image products. Images are produced from the best available original document. 
In the last approach, small inorganic building units are assembled around organic templates to form ordered structures that have narrow PSDs. Such a templating approach has been used since the 1950s to synthesize microporous molecular sieves. ${ }^{4}$ In the case of molecular sieves, individual organic molecules are used as templates. By using an ensemble of organic molecules to create a larger template, this method has been extended to the synthesis of ordered mesoporous materials.

\section{SYNTHESIS OF PERIODIC MESOPHASES: MOLECULAR ASSEMBLY FROM HOMOGENEOUS SOLUTIONS}

Periodic mesoporous oxides can be synthesized by templating molecular metal oxide precursors around surfactant assemblies. ${ }^{5.10}$ Four reagents are necessary: a source of the small metal-oxide ions, a surfactant, a solvent, and a chemical to adjust the $\mathrm{pH}$. In our syntheses, we introduce a source of silica (tetramethoxysilane, TMOS) into a basic aqueous solution of a micelle-forming cationic surfactant. The TMOS is hydrolyzed to form small anionic oligomers that can coordinate with the surfactant headgroups. The strong interaction between the silica species and the surfactants leads to phase separation of the silica/surfactant arrays into microdomains that have an ordered liquid crystalline structure. The surfactants can be removed from the inorganic network by washing or calcination.

Our solvent consists of a mixture of water and a cosolvent. The cosolvent aids in the hydrolysis of the silica source and allow us to form homogeneous reaction systems, from which high quality materials can rapidly be formed. In this report we will focus on the cosolvents methanol, formamide, and THF.

Typical syntheses use $0.2 \mathrm{~g}$ cetyltrimethylammonium bromide $\left(\mathrm{C}_{16} \mathrm{TABr}, 0.55\right.$ mmol), $9.8 \mathrm{~g}$ water plus cosolvent (e.g. $7.35 \mathrm{~g} \mathrm{H}_{2} \mathrm{O}+2.45 \mathrm{~g} \mathrm{CH}_{3} \mathrm{OH}$ for a $75 / 25$ mixture), $0.065 \mathrm{~mL} 50 \mathrm{wt} \%$ aqueous $\mathrm{NaOH}(1.14 \mathrm{mmol})$, and $0.625 \mathrm{~mL}$ TMOS (4.19 mmol).

\section{SILICA SOURCE: A KEY TO HOMOGENEOUS SOLUTIONS}

To form homogeneous solutions we sought a silica source that rapidly provides molecular silica species when added to an aqueous solution. We examined silicon alkoxide precursors, $\mathrm{Si}(\mathrm{OR})_{4}$ with $\mathrm{R}=\mathrm{OC}_{2} \mathrm{H}_{5}$ (TEOS) and $\mathrm{R}=\mathrm{OCH}_{3}$ (TMOS).

The use of TEOS results in the formation of inhomogeneous solutions owing to its initial immiscibility with water. Micron size TEOS droplets form when the solution is rapidly stirred. With an optical microscope we observed that the droplets slowly expand. We believe that the outer surfaces of the droplets are hydrolyzed first and form a shell of amorphous silica around the TEOS rich interior. Then, as water infuses these shells to hydrolyze the TEOS inside, the pods swell. Eventually these pods burst and expel silicate oligomers, leaving behind complex amorphous silica shells that reduce the reaction yield.

The use of TMOS results in the formation of a homogeneous solution within seconds of its addition to the precursor solution. No shell formation has been detected in the TMOS/cosolvent systems.

In addition to influencing the homogeneity of the reaction mixture, the silica source strongly influences the kinetics of mesophase formation. Nonmolecular sources of silica require long digestion times to break down larger structures into molecular species suitable for mesophase formation. Molecular sources of silica require much shorter times to hydrolyze and form periodic products. Products form in 7 seconds at $25^{\circ} \mathrm{C}$ with TMOS and are periodic in less than one minute (Figure 1). The formation of periodic products from TEOS 
requires about two orders of magnitude longer. The rate determining step for product formation thus appears to be the hydrolysis of the alkoxide, as TEOS is known to hydrolyze much more slowly than TMOS owing to its bulkier R-group. ${ }^{3}$

Reaction temperature significantly affects the hydrolysis rate of metal alkoxides. We sought to predictably alter the mesophase reaction time by changing the synthesis temperature. By using $\mathrm{C}_{16} \mathrm{TABr}$ with methanol or formamide as cosolvents we were able to make periodic products in the range from $10{ }^{\circ} \mathrm{C}$ to $100{ }^{\circ} \mathrm{C}$. At $<10{ }^{\circ} \mathrm{C}, \mathrm{C}_{16} \mathrm{TABr}$ phase separates.

To make products at $<10^{\circ} \mathrm{C}$, we used the sulfate salt of $\mathrm{C}_{16} \mathrm{TA}^{+}\left(\mathrm{C}_{16} \mathrm{TAHSO}_{4}\right)$. The $\mathrm{C}_{16} \mathrm{TAHSO}_{4}$ remains dissolved in solution to very low temperatures and allows periodic products to be formed as low as $-14^{\circ} \mathrm{C}$. The kinetics exhibit Arrhenius behavior from -14 ${ }^{\circ} \mathrm{C} \leq \mathrm{T} \leq 100^{\circ} \mathrm{C}$ ( Figure2).

Finally, the silica source influences the tertiary structure of the mesophase. The rapid hydrolysis of the alkoxide generates hydrolyzed species throughout the reaction volume. As these species interact with the surfactants, the local concentration of each increases and the assemblies begin to phase separate into microdomains. Invariably, phase separation leads to physical gels composed of submicron crystallites.

At the time of phase separation, the surface of the silica/surfactant crystallites contain a large number of reactive hydroxyl and methoxy groups (from ${ }^{29} \mathrm{Si} N M R, \mathrm{Q}^{3} / \mathrm{Q}^{4}=2.1$ after 5 minutes). Such species can readily chemically crosslink with the elimination of water or methanol to form Si-O-Si bonds. We believe that the rapid formation of crystallites throughout the reaction volume that have a high concentration of hydroxyl and methoxy groups assists the formation of physical gels.

Figure 1. In situ X-ray diffraction of mesophases made at $25{ }^{\circ} \mathrm{C}$ from a $2 \mathrm{wt} \% \mathrm{C}_{16} \mathrm{TABr}$ in $75 / 25$ water/methanol solution. All samples gelled in $7 \mathrm{~s}$. Aging times are shown on the right. The inset shows part of the spectrum for the sample aged 1 minute. 
Figure 2. Mesophases made from $2 \mathrm{wt} \%$ surfactant solutions in $75 / 25$ water cosolvent solutions exhibit Arrhenius behavior over a large temperature range. Symbols identify the cosolvent: circles - Nmethylformamide/ $\mathrm{C}_{16} \mathrm{TAHSO}_{4}$; triangles - methanol/ $\mathrm{C}_{16} \mathrm{TAHSO}_{4}$; diamonds - methanol/C $\mathrm{C}_{16} \mathrm{TABr}$.

\section{COSOLVENTS: HOMOGENEOUS SOLUTIONS AND SOLUTION THERMO- DYNAMICS}

The organization of molecular silica and surfactant precursors into an inorganic/organic array depends on a thermodynamic phase transition. By using cosolvents we can alter the solution thermodynamics and exert a measure of control over the synthetic process. For example, cosolvents allow nonaqueous synthesis, enable the pore diameter to be tuned, and allow transformations from a hexagonal to a lamellar structure.

\section{Nonaqueous Synthesis With Polar Cosolvents}

Substantially nonaqueous solvents (minimum water to cosolvent ratio, $\mathrm{p}$, equal to 7/93) can be used to synthesize periodic products in the water/formamide system (Figure 3). At $p=7 / 93$, the water to silica molar ratio, $r$, is 7 to 1 . Thus water serves mainly as a reagent to hydrolyze the TMOS (2:1 limiting ratio). The products obtained from the nonaqueous preparations are generally stable to calcination. At $p=4 / 96(r=5.2 / 1)$ the diffraction pattern shows only one peak, which is consistent with very small domain sizes. Finally, at $\mathrm{p}=1 / 99(\mathrm{r}=1.3 / 1)$ a clear, transparent chemical gel forms.

\section{Cosolvents And Pore Size Control}

The use of cosolvents results in monotonic changes in the unit cell size of the mesophase with cosolvent concentration. For example, increasing methanol concentration leads to a $5 \AA$ decrease in unit cell constant over the range in which periodic products can be formed (100/0 to 40/60; Figure 4).

The change in cell constant can result from a change in the inorganic wall thickness, or a change in the diameter of the pore, or a combination of the two. Data from dynamic light scattering show that the radius of the micelle in the precursor solution decreases with 
Figure 3. X-ray diffraction spectra for as-synthesized (bottom) and calcined (top) mesophases. Sample was prepared from a $2 \%$ CTAB solution with a water/formamide ratio of $10 / 90$. The water to silicon ratio is 13 . Sample was calcined in $\mathrm{O}$ at $550^{\circ} \mathrm{C}$ for $\sim 10 \mathrm{~h}$. The unit cell size decreases from 39.1 (4) $\AA$ in the uncalcined sample to 35.9 (6) $\AA$ in the calcined samples, a 9\% decrease.

increased methanol concentration. Isothermal $\mathrm{N}_{2}$ adsorption data from a limited number of samples show that wall thicknesses of the samples made with methanol are comparable to those found for samples made without methanol (i.e. 9-11 $\AA$ ). From these observations we conclude that it is the change in pore size that most strongly contributes to the change in cell parameter.

The use of cosolvents allows the pore diameter of the mesophase to be tuned over a finer range than can be achieved by changing the tail length of the surfactant by one $-\mathrm{CH}_{2}-$

Figure 4. The cell constants of mesophases prepared from homogeneous $2 \%$ CTAB solution in water/methanol mixtures decrease as the methanol concentration increases. The slope is $-8.2 \AA / 100 \mathrm{wt} \%$. In the range where periodic products can be made (100/0 to $40 / 60)$, the cell can be continuously tuned over $\sim 5$ $\AA$. 
unit $(\sim 2.53 \AA ; 1.265 \AA$ per carbon $\times 2$ monomers per pore diameter). In fact, the diameter can be continuously tuned over several angstroms by choosing the concentration of the cosolvent.

\section{Structural Control With Nonpolar Cosolvents}

Nonpolar cosolvents can be used to alter the structure of the mesophase. We first observed this phenomenon in the water/THF series (Figure 5). Detail study of the region from $p=100 / 0$ to $p=80 / 20$ shows that as the concentration of THF increases the hexagonal, $\mathrm{H}$, product becomes less crystalline and eventually the structure is lamellar, $\mathrm{L}$ The phase boundary is at $p=82 / 18$ water/THF (for samples aged $3 \mathrm{~d}$ ).

Aging time, $t_{\text {age }}$ can also be used to transform a structure from hexagonal to lamellar. For example, samples synthesized in $\mathrm{THF} /$ water very near their $\mathrm{H}$ to $\mathrm{L}$ phase boundary are initially hexagonal; after aging for $1 \mathrm{~d}$ they transform to lamellar.

This time-dependent behavior implies that the system is not at equilibrium. It seems likely that the equilibrium partitioning of the cosolvent is changed when micelles coalesce into liquid crystalline tubes. After the mesophase forms, the micelle tails are presumably less densely packed than they were in spherical micelles. The reduced packing density may lead to a slight increase in the solubility of the nonpolar cosolvent in the tails. Increasing the concentration of the cosolvent in the tails increases the hydrophobic volume, of the organic phase, which increases the favorability of a lamellar arrangement of the surfactants.

A second consideration is that for the inorganic phase to transform from a curved to a flat surface, some $\mathrm{Si}-\mathrm{O}-\mathrm{Si}$ bond angles must be relaxed and any bonds between parallel layers must be broken. This is possible as the bonds are quite labile shortly after product formation and the network is far from fully condensed $\left(Q^{3} / Q^{4}\right.$ is high) so it is flexible.

Figure 5. X-ray diffraction data on mesophases prepared from homogeneous $2 \% \mathrm{C}_{16} \mathrm{TABr}$ solution in 
It is assumed that silicate oligomers displace counterions at the surfactant water interface as the initial step in mesophase formation. If this is the case, it should be possible to alter the reaction kinetics and potentially inhibit mesophase formation by using anions that strongly bond to the head groups. We have examined the effect of mono-, di-, and trivalent anions that have one or more binding sites to determine their effect on mesophase formation. We used the salts $\mathrm{KI}, \mathrm{K}_{2} \mathrm{SO}_{4}, \mathrm{NaCl}, \mathrm{NaH}_{2} \mathrm{PO}_{4}$ (titrated to $\mathrm{pH} 13$ with $\mathrm{NaOH}$ ) and $\mathrm{K}_{2} \mathrm{C}_{2} \mathrm{O}_{4}$ in concentrations up to $2.5 \mathrm{M}$.

In general at anion concentrations greater than $0.5 \mathrm{M}$ (salt:silica $<1.2: 1$ ) added salt has no measurable effect on cell constants or gelation time. From studies of $2.0 \mathrm{M}$ solutions of $\mathrm{Cl}^{-}, \mathrm{F}^{-}, \mathrm{C}_{2} \mathrm{O}_{4}{ }^{2-}$, and $\mathrm{PO}_{4}{ }^{3-}$, we find that only oxalate has a significant effect on gel time $(>30 \%)$ and that the affinity of the anions for the cationic organic array increases in the order $\mathrm{F}^{-} \approx \mathrm{Cl}^{-}<\mathrm{PO}_{4}{ }^{3-}<\mathrm{C}_{2} \mathrm{O}_{4}{ }^{2-}<$ silicate.

The effect of oxalate ion on gel kinetics is zero order at oxalate:Si ratios less than 1.2 to 1 (i.e. $0.5 \mathrm{M}$ salt). At ratios greater than $1.2: 1$, there is a first order dependence of gel time on oxalate ion concentration (Figure 6). This behavior implies that oxalate ions are able to effectively compete with silicate anions for binding sites at the head group when present in concentrations greater than the silicate species. It is interesting to note that the oxalate: $\mathrm{C}_{16} \mathrm{TA}^{+}$ratio in the $0.5 \mathrm{M}$ salt solution is $\sim 9: 1$. This means that there is about 18 times more oxalate ions in solution than would be necessary to completely balance the charge on the surfactant head groups. Clearly the oxalate ions can completely encrust the surfactant assemblies and be present in the double layer before they affect gel kinetics.

Increasing the oxalate concentration also increases the cell constant from $44 \AA$ to 49 $\AA$. The increase in lattice parameter is consistent with previous observations that addition of a neutral electrolyte to solutions of ionic surfactants in aqueous solutions cause an increase in aggregation number and volume of the surfactant assemblies. ${ }^{11}$

The high oxalate salt concentrations also have an effect on crystallite size and the textures of the aggregates. For example, adding $2.0 \mathrm{M} \mathrm{K}_{2} \mathrm{C}_{2} \mathrm{O}_{4}$ to the solution decreases the crystallite size by an order of magnitude.

\section{PROPERTIES OF MESOPHASES MADE FROM HOMOGENEOUS SOLUTIONS}

Products formed from homogeneous solutions virtually always lead to gels of periodic surfactant/silica composites that display exceptional periodicity. For a wide variety of cosolvents and reaction temperatures, these systems yield smooth spherical or ellipsoidal particles that range in size from 150 to $500 \mathrm{~nm}$.

Periodic hexagonal mesophases made from homogeneous solutions with TMOS form at least an order of magnitude faster than for any other reported, yet provide diffraction spectra that indicate large domain sizes. For example, mesophases made from homogeneous solutions form in less than $10 \mathrm{~s}$, display 4 diffraction peaks in less than 1 minute, and exhibit domain sizes up to $140 \mathrm{~nm}$ at aging times as short as $4 \mathrm{~h}$ at $25^{\circ} \mathrm{C}$.

Shortly after the mesophases have been formed, the extent of condensation of the silicate framework is quite low. For example, ${ }^{29} \mathrm{Si} N M R$ results indicate a $\mathrm{Q}^{3} / \mathrm{Q}^{4}$ ratio greater than 2.1 for a sample isolated after $5 \mathrm{~min}$ (spectrum recorded over $18 \mathrm{~h}$ ). Despite the low degree of condensation, samples are thermally stable at short times. Periodic composites can be isolated after $5 \mathrm{~min}$ and immediately calcined to periodic porous silica. Calcined samples (75/25 water/methanol) exhibit apparent BET surface areas in excess of 900 
Figure 6. Gel time for samples made in solutions that contain $\mathrm{K}_{2} \mathrm{C}_{2} \mathrm{O}_{4}$ show no detectable effect of the ion at low concentration, but exhibit linear dependence at higher concentrations.

$\mathrm{m}^{2} / \mathrm{g}$ and pore volumes $\approx 0.6 \mathrm{cc} / \mathrm{g}$. From TGA results the lower limit of $\mathrm{C}_{16} \mathrm{TA}^{+}: \mathrm{Si}$ is 0.16 , which is the same as the ratio of $\mathrm{C}_{16} \mathrm{TABr}$ to TMOS.

\section{THE SYNTHETIC APPROACH}

Forming mesophase gels from homogenous solutions is a new approach to the synthesis of mesoporous materials. The synthesis is fast, minimizes by-products, and provides hexagonal mesoporous products that exhibit large coherent scattering lengths and thermal stability at short aging times. The approach also decreases the temperature at which the surfactant is soluble, which eliminates the need to heat the precursor solution.

\section{ACKNOWLEDGMENTS}

We thank S. Prabakar for NMR results and Mark Rodriguez for coherent scattering domain data. This work was funded by the United States Department of Energy under Contract No. DE-AC04-94AL-85000.

\section{REFERENCES}

1. D. H. Everett, in: "IUPAC Manual of Symbols and Terminology, Pure Appl. Chem." 31, 578 (1972).

2. P. Behrens, Mesoporous Inorganic Solids, Adv. Mater. 5(2), 127-132 (1993). 
3. C. J. Brinker and G. W. Scherer, in: "Sol-Gel Science," Academic, New York (1990).

4. D. W. Breck, in: "Zeolite Molecular Sieves," Wiley, New York (1974).

5. J. S. Beck, J. C. Vartuli, W. J. Roth, M. E. Leonowicz, C. T. Kresge, K. D. Schmitt, C. T-W. Chu, K. H. Olson, E. W. Sheppard, S. B. McCullen, J. B. Higgins, and J. L Schlenker, A New Family of Mesoporous Molecular Sieves Prepared with Liquid Crystal Templates, J. Am. Chem. Soc. 114, 10834-10843 (1992).

6. C. T. Kresge, M. E. Leonowicz, W. J. Roth, J. C. Vartuli, and J. S. Beck, Ordered Mesoporous Molecular Sieves Synthesized by a Liquid-Crystal Templating Mechanism, Nature, 359, 710-712 (1992).

7. A. Monnier, F. Schuth, Q. Huo, K. Dumar, K. Margolese, R. S. Maxwell, G. D. Stucky, M. Krishnamurty, P. Petroff, A. Firouzi, M. Janicke, and B. F. Chmelka, Cooperative Formation of Inorganic-Organic Interfaces in the Synthesis of Silicate Mesostructures, Science, 261, 1299-1303 (1993).

8. Q. Huo, K. I. Margolese, U. Ciesla, P. Feng, T. E. Gier, P. Sieger, R. Leon, P.M. Petroff, F. Schuth, G. D. Stucky, "Generalized Synthesis of Periodic Surfactant/Inorganic Composite Materials," Nature, 24, 317-321 (1994).

9. Q. Huo, D. I. Margolese, U. Ciesla, D. G. Demuth, P. Feng, T. E. Gier, P. Sieger, A. Firouzi, B. F. Chmelka, F. Schuth, and G. D. Stucky, "Organization of Organic Molecules with Inorganic Molecular Species into Nanocomposites Biphase Arrays," Chem. Mater., 6, 1176-1191 (1994).

10. P. T. Tanev and T. J. Pinnavaia, "A Neutral Templating Route to Mesoporous Molecular Sieves," Science, 267, 865-867 (1995).

11. M. J. Rosen, Chapter 4: Solubilization by solutions of surfactants: Micellar catalysis, in: "Surfactants and Interfacial Phenomena," Wiley, New York (1989). 


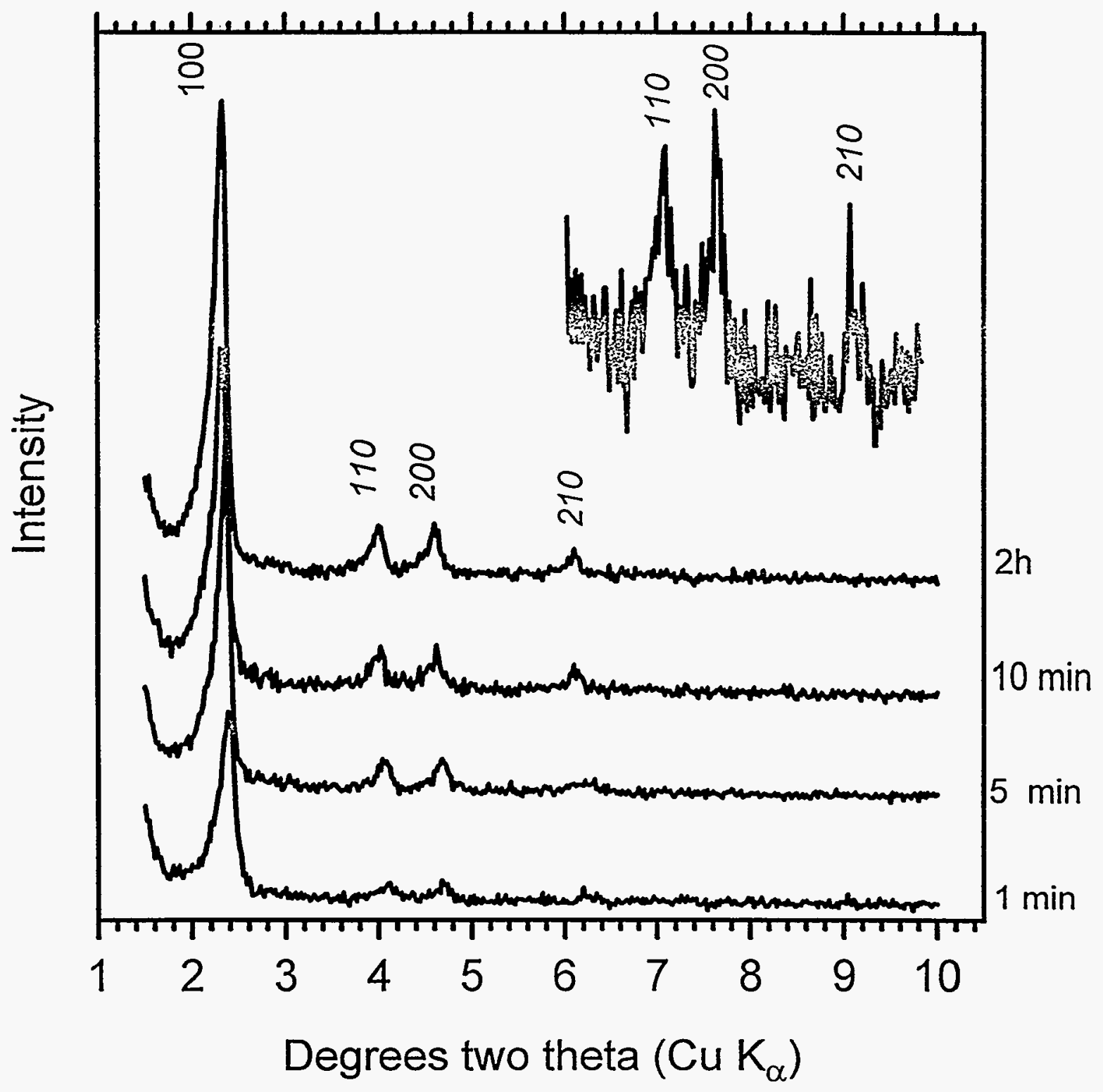

Anderson et. al. Figure 1 


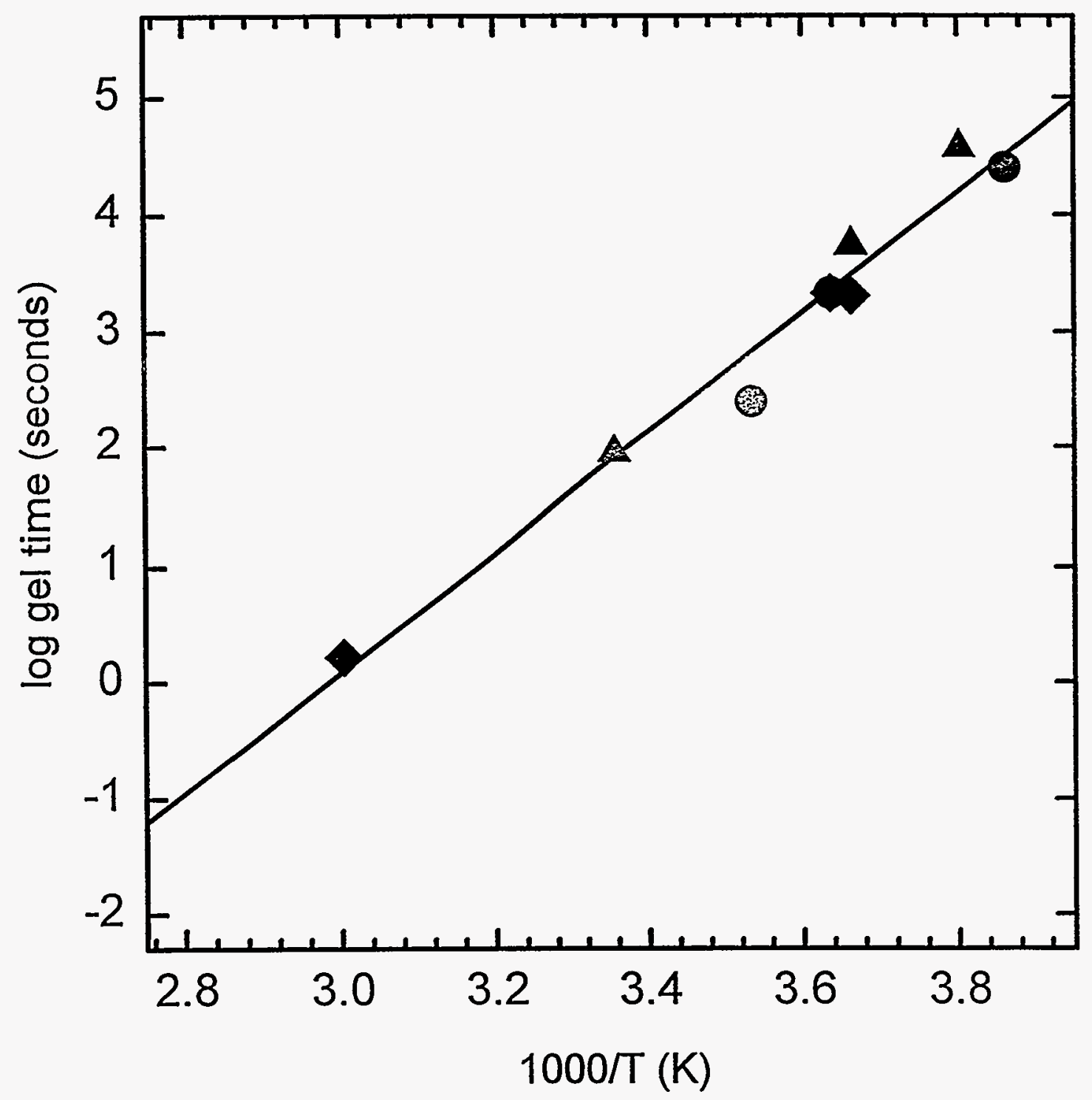

Anderson et. al. Figure 2 


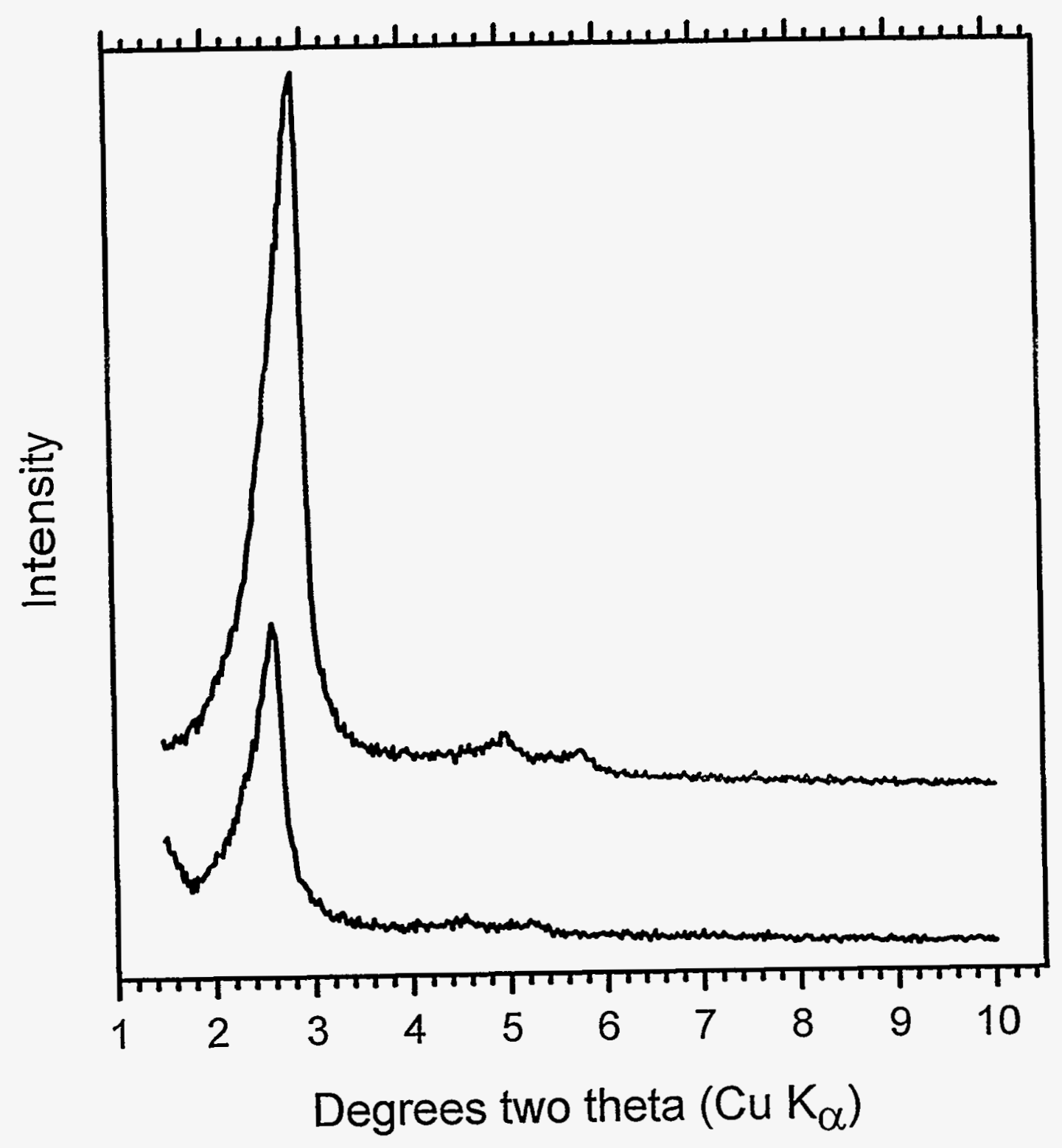

Anderson et. al. Figure 3 


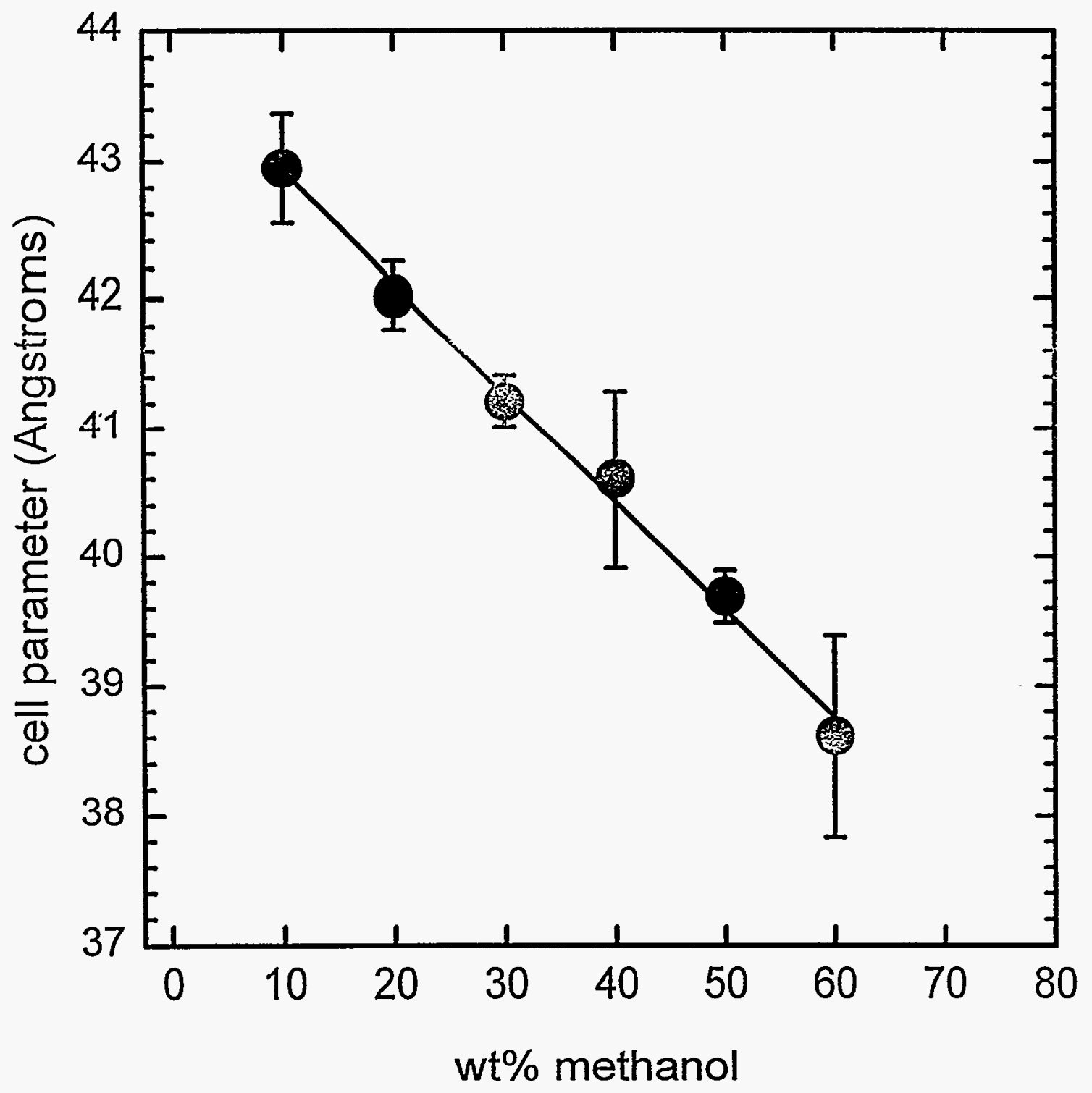

Anderson et. al. Figure 4 


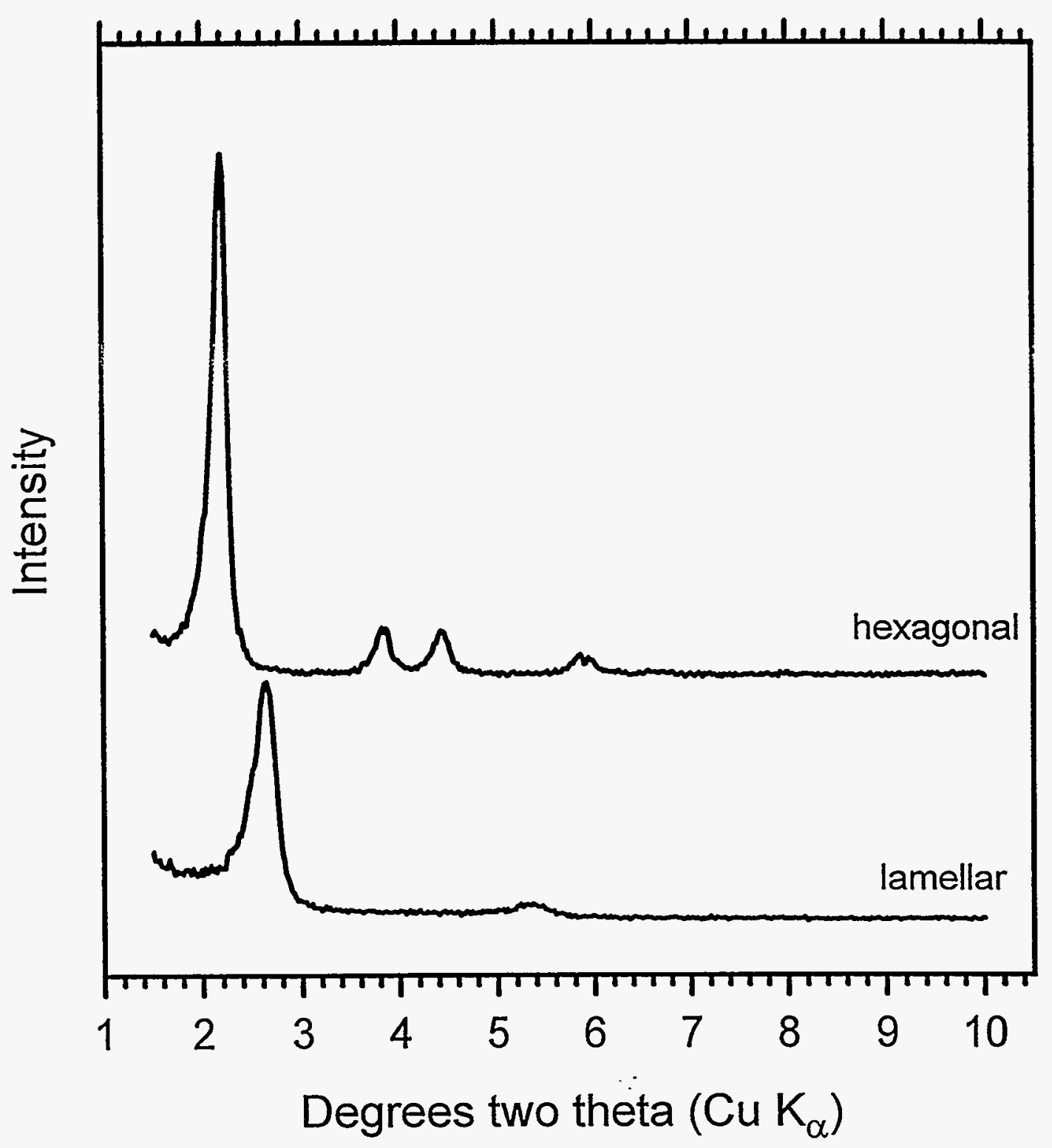




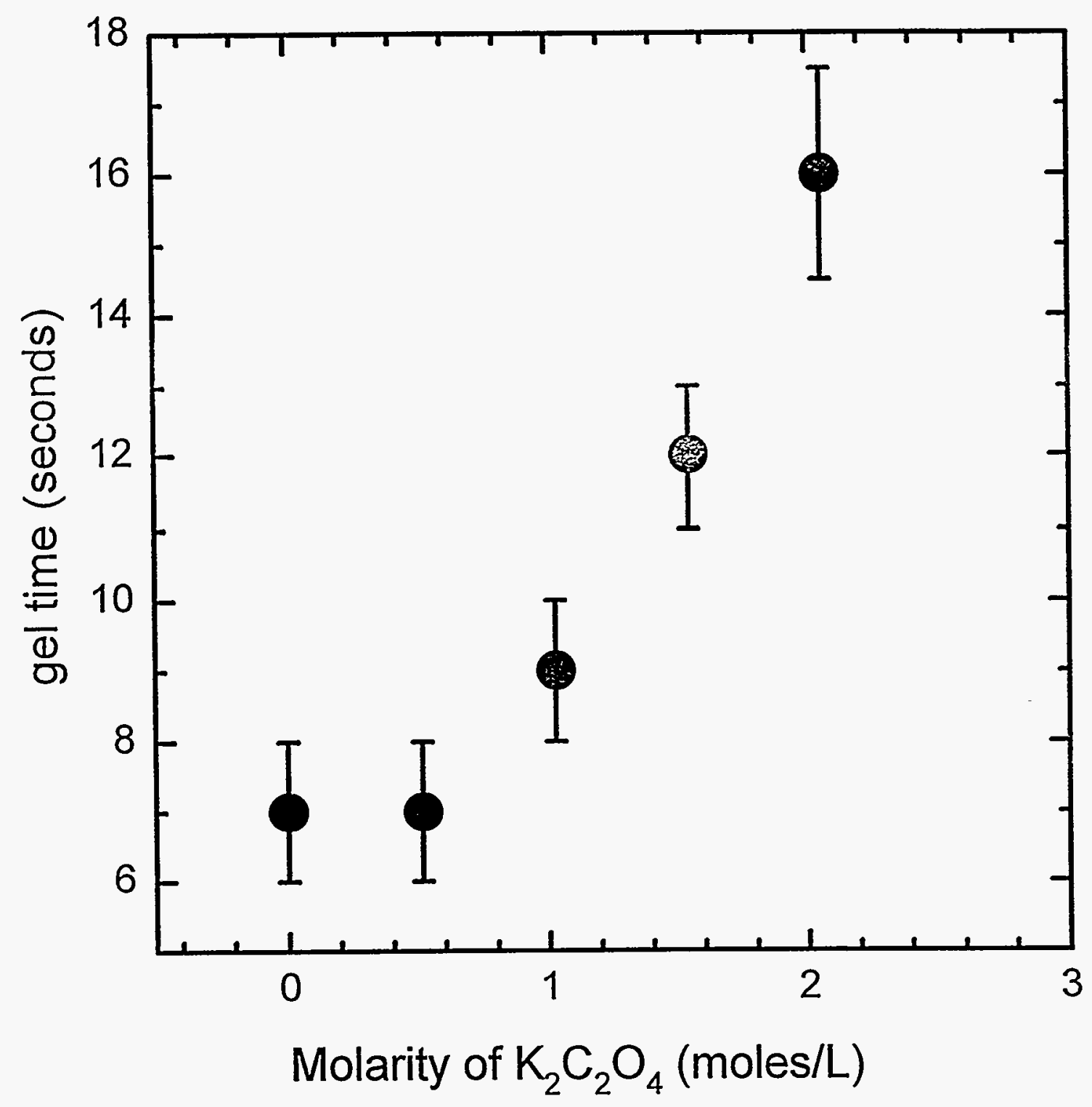

Anderson et. al. Figure 6 


\section{REFERENCES}

1. D. H. Everett, in: "IUPAC Manual of Symbols and Terminology, Pure Appl. Chem." 31,578 (1972).

2. P. Behrens, Mesoporous Inorganic Solids, Adv Mater. 5(2), 127-132 (1993).

3. C. J. Brinker and G. W. Scherer, Chapter 13: Film formation, in: "Sol-Gel Science," Academic, New York (1990).

4. D. W. Breck, in: "Zeolite Molecular Sieves," Wiley, New York (1974).

5. J. S. Beck, J. C. Vartuli, W. J. Roth, M. E. Leonowicz, C. T. Kresge, K. D. Schmitt, C. T-W. Chu, K. H. Olson, E. W. Sheppard, S. B. McCullen, J. B. Higgins, and J. L Schlenker, A New Family of Mesoporous Molecular Sieves Prepared with Liquid Crystal Templates, J. Am. Chem. Soc. 114, 10834-10843 (1992).

6. C. T. Kresge, M. E. Leonowicz, W. J. Roth, J. C. Vartuli, and J. S. Beck, Ordered Mesoporous Molecular Sieves Synthesized by a Liquid-Crystal Templating Mechanism, Nature, 359, 710-712 (1992). ??

7. A. Monnier, F. Schuth, Q. Huo, K. Dumar, K. Margolese, R. S. Maxwell, G. D. Stucky, M. Krishnamurty, P. Petroff, A. Firouzi, M. Janicke, and B. F. Chmelka, Cooperative Formation of Inorganic-Organic Interfaces in the Synthesis of Silicate Mesostructures, Science, 261, 1299-1303 (1993).

8. Q. Huo, R. I. Margolese, U. Ciesla, P. Feng, T. E. Gier, P. Sieger, R. Leon, P.M. Petroff, F. Schuth, G. D. Stucky, "Generalized Synthesis of Periodic Surfactant/Inorganic Composite Materials," Nature, 24, 317-321 (1994).

9. Q. Huo, D. I. Margolese, U. Ciesla, D. G. Demuth, P. Feng, T. E. Gier, P. Sieger, A. Firouzi, B. F. Chmelka, F. Schuth, and G. D. Stucky, "Organization of Organic Molecules with Inorganic Molecular Species into Nanocomposites Biphase Arrays," Chem. Mater., 6, 1176-1191 (1994).

10. P. T. Tanev and T. J. Pinnavaia, "A Neutral Templating Route to Mesoporous Molecular Sieves," Science, 267, 865-867 (1995).

11. C. J. Brinker and G. W. Scherer, Chapter 2: Hydrolysis and condensation of silicon alkoxides, in: "Sol-Gel Science," Academic, New York (1990).

12. M. J. Rosen, Chapter 4: Solubilization by solutions of surfactants: Micellar catalysis, in: "Surfactants and Interfacial Phenomena," Wiley, New York (1989).

\section{DISCLAIMER}

This report was prepared as an account of work sponsored by an agency of the United States Government. Neither the United States Government nor any agency thereof, nor any of their employees, makes any warranty, express or implied, or assumes any legal liability or responsibility for the accuracy, completeness, or usefulness of any information, apparatus, product, or process disclosed, or represents that its use would not infringe privately owned rights. Reference herein to any specific commercial product, process, or service by trade name, trademark, manufacturer, or otherwise does not necessarily constitute or imply its endorsement, recommendation, or favoring by the United States Government or any agency thereof. The views and opinions of authors expressed herein do not necessarily state or reflect those of the United States Government or any agency thereof. 